\title{
Comparative ROV surveys reveal jellyfish blooming in a deep-sea caldera: the first report of Earleria bruuni from the Pacific Ocean
}

\author{
MITSUKO HIDAKA-UMETSU ${ }^{1,2}$ AND DHUGAL J. LINDSAY ${ }^{1,2}$ \\ ${ }^{1}$ School of Marine Bioscience, Kitasato University, Sagamihara, Kanagawa, Japan, ${ }^{2}$ Japan Agency for Marine-Earth Science and \\ Technology (JAMSTEC), Yokosuka, Kanagawa, Japan
}

\begin{abstract}
Large numbers of the leptomedusa Earleria bruuni were observed inside a semi-closed deep-sea caldera during a comparative survey of the macrozooplankton fauna inside and outside the Kurose Hole, Izu-Ogasawara Islands, by the remotely operated vehicle (ROV) 'Dolphin-3K', on 24 September 200o. The Kurose Hole is an inactive volcanic caldera of $790 \mathrm{~m}$ bottom depth, located within the Izu-Bonin island arc, south of Tokyo. Archived video and audio data from a dive by the human-occupied vehicle (HOV) 'Shinkai 200o', carried out 3 weeks after the ROV dives, was also analysed. During all dives within the caldera, E. bruuni was present in large numbers and, during the HOV dive, two specimens for morphological analysis were obtained. Herein, we report E. bruuni from the Pacific Ocean for the first time. The vertical profiles of environmental factors and the vertical distributions of gelatinous macrozooplankton taxa such as salps, ctenophores, hydromedusae, siphonophores and scyphomedusae, were extremely different inside and outside the caldera. Inside the caldera the water temperatures were warm and dissolved oxygen levels were high compared with outside. For each taxon, their distributions were characterized and compared between the inside and outside of the caldera, and with previous literature reports.
\end{abstract}

Keywords: Blooming, deep-sea caldera, Earleria bruuni, gelatinous macrozooplankton, underwater vehicles

Submitted 17 March 2017; accepted 20 July 2017; first published online 22 August 2017

\section{INTRDDUCTION}

Gelatinous macrozooplankton such as jellyfishes have been reported to bloom in response to anthropogenic eutrophication, climate change and/or human activities such as overfishing (Purcell, 2012). Recent research using submersibles and remotely operated vehicles (ROVs) has revealed that gelatinous macrozooplankton are also ubiquitous and predominant taxa in the deep sea (e.g. Lindsay \& Hunt, 2005; Robison et al., 2010).

Recently in the deep sea, a new anthropogenic risk to the marine environment through seafloor mining has arisen and it has been predicted that impacts will extend not just to the seafloor but to all marine environments including the water column (Boschen et al., 2013). Pre-emptively, proposed requirements for Environmental Impact Assessments (EIAs) related to these activities have been investigated (Boschen et al., 2013). Because mineral resource-rich areas, such as seafloor massive sulphide (SMS)-rich areas, include rare and unique benthic communities (e.g. chemosynthetic communities supported by hydrothermal vents), the possible impacts on these environments have attracted more study (e.g. Van Dover, 2014; Boschen et al., 2015; Nakajima et al., 2015). In

Corresponding author:

M. Hidaka-Umetsu

Email: mitsukou@jamstec.go.jp contrast, the effects on the macrozooplankton fauna through anthropogenic disturbances have barely attracted attention, even though gelatinous macrozooplankton could well be important predators of larvae and other plankton around such communities (Lindsay et al., 2015; Phillips, 2017). Scyphomedusae, hydrozoans (hydromedusae, siphonophores) and ctenophores are all known to exponentially increase their numbers when environmental conditions become favourable (e.g. Purcell, 2005; Uye, 2008; Abe et al., 2014). The hydrozoan Hydra has been used for biological toxicity testing in freshwater ecosystems (e.g. Arkhipchuk et al., 2006; Quinn et al., 2012), and hydrozoan medusae might also be useful for bioassays in the ocean. Compared with micro- and mesozooplankton, gelatinous macrozooplankton are easier to survey visually, in a non-destructive, environmentally friendly way. To investigate the possibility of using non-destructive technology like image-based observations (e.g. ROV surveys) and using gelatinous macrozooplankton as indicator organisms, we investigated their distribution and diversity in an area that may be targeted for deep sea mineral mining.

The Izu-Bonin Arc, within the southern part of Japan's exclusive economic zone (EEZ), is known to contain large SMS deposits. A semi-closed caldera within this arc was selected for the present study. This caldera, the Kurose Hole, is about $5-7 \mathrm{~km}$ diameter, with the depth of its rim at around $250 \mathrm{~m}$ at its deepest point and $114 \mathrm{~m}$ at its shallowest point, and with the maximum depth of the caldera floor being 
just over $790 \mathrm{~m}$ depth (Iwabuchi et al., 1989; Yuasa et al., 1991). Water temperatures inside the caldera are several degrees warmer than those outside (Iwabuchi et al., 1989). This makes it an ideal site to study how the vertical distributions of gelatinous macrozooplankton are related to the physico-chemical characteristics of their aqueous environment. Video data from ROV dives inside and outside the Kurose Hole, along with supplementary data from a crewed submersible dive within the caldera, were analysed for the present study.

\section{MATERIALS AND METHODS}

\section{Data collection}

Data were collected using the ROV 'Dolphin- $3 \mathrm{~K}$ ' and the human-occupied vehicle (HOV) 'Shinkai 2000' in the Kurose Hole $\left(33^{\circ} 24^{\prime} \mathrm{N} 139^{\circ} 41^{\prime} \mathrm{E}\right.$, Figure 1), which is located in the Izu-Bonin Arc, due south of Tokyo (Yuasa et al., 1991). Two 'Dolphin-3K' dives (3K488, 3 K489) were performed inside and outside the Kurose Hole, respectively, on 24 September 2000 during the RV 'Natsushima' cruise NToo-10, as pre-dive safety surveys for subsequent 'Shinkai 2000' dives. Although one dive inside and one dive outside the Kurose Hole caldera were planned for cruise NToo-11 of the RV 'Natsushima', due to bad weather conditions only one dive was carried out. This was 'Shinkai 2000' Dive 1227, inside the Kurose Hole on 17 October 2000. Observations were made and video recorded from the surface to the seafloor in order to analyse the community composition of the midwater gelatinous macrozooplankton.

\section{Details of survey platforms}

\section{DOLPHIN-3K}

The 'Dolphin- $3 \mathrm{~K}$ ' was equipped with a Victor/JVC KY-F32 three chip CCD camera and six lights: three 400-SeaArc HMI/MSR forward-facing metal halide lamps and three $250 \mathrm{~W}$ SeaLine SL-120/250 halogen lamps (one in the rear, two in the front). Video footage was recorded on BCT-D124L Digital Betacam tapes, which were reviewed in their entirety, animals being identified wherever possible. Specimens were collected for positive identification using a single canister suction sampler $(3 \mathrm{~K} 488)$ or an 18 -canister suction sampler $\left(3 \mathrm{~K}_{4} 89\right)$ and were transferred to shipboard aquaria for positive identification. Environmental parameters (pressure, temperature, conductivity, dissolved oxygen concentration) were measured using a SeaBird SBE19 CTD with an SBE13 oxygen sensor attached to the vehicles, and depth, salinity and water density were calculated from these parameters. Physico-chemical parameters were correlated to the presence of a given animal by matching the time on the CTD dataset to the time on the video.

\section{SHINKAI 2000}

The 'Shinkai 2000' was equipped with a Victor GF-S10oo HU three chip, CCD camera specially modified for the vehicle.

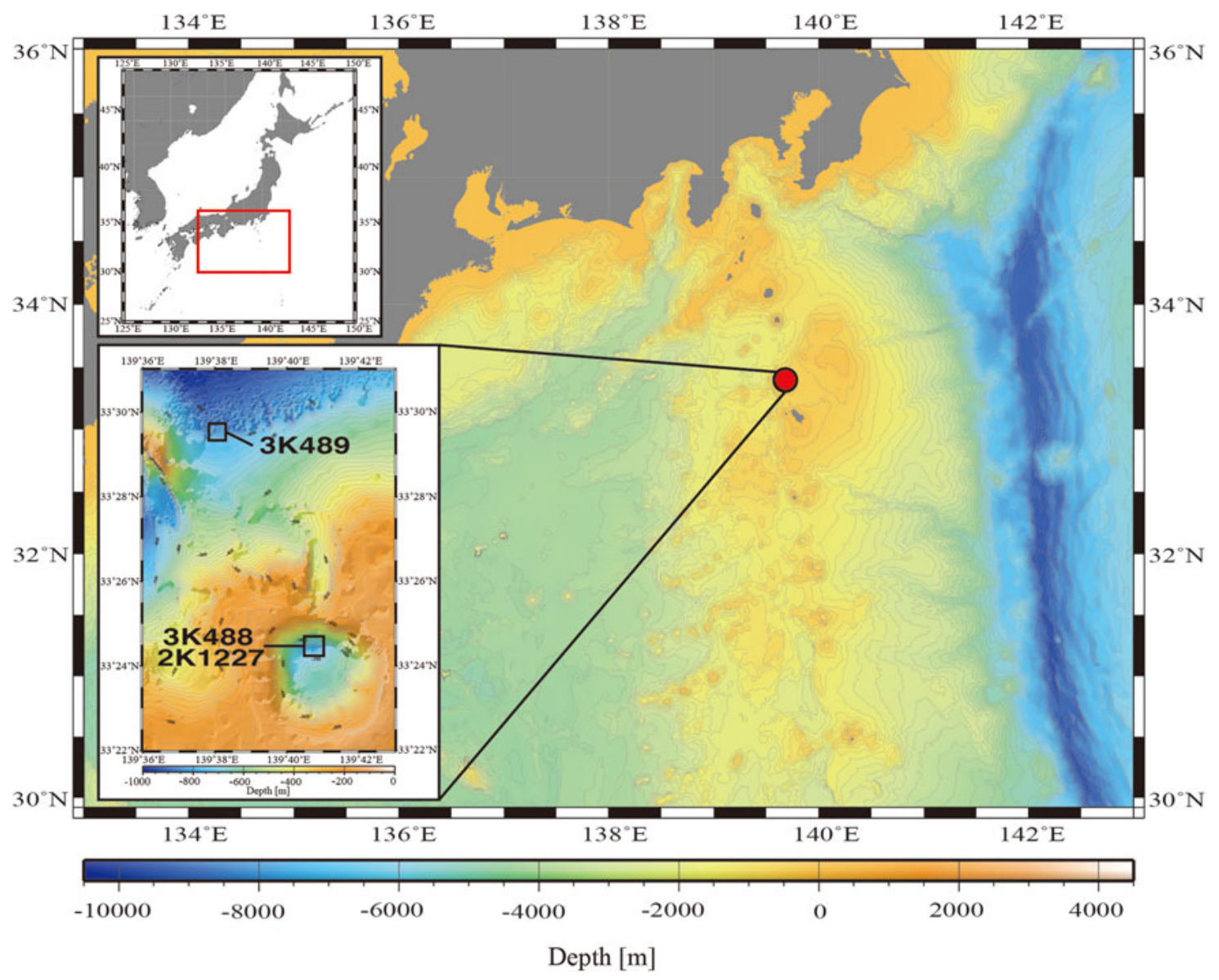

Fig. 1. Map showing the dive locations. 
There were eight lights: five $250 \mathrm{~W}$ SeaLine SL-120/250 halogen lamps and three $400 \mathrm{~W}$ SeaArc $\mathrm{HM}_{1} / \mathrm{MSR}$ metal halide lamps. Video footage was recorded on BCT-D124L Digital Betacam tapes. Specimens were collected for positive identification using a 6-canister suction sampler and a gate valve sampler (see Hunt et al., 1997). Physico-chemical data were collected and correlated with observations as above. During the midwater dive, comments by the observer (DJL) were recorded on the audio track of the tapes and the observational database that resulted from this dive therefore consisted of both video-recorded data and live observations made through the observation port of the vehicle.

\section{Observational analysis}

\section{DISTRIBUTION AND COMMUNITY COMPOSITION}

To compare the distribution and community composition of gelatinous macrozooplankton inside and outside the Kurose Hole, both 'Dolphin- $3 \mathrm{~K}$ ' dives 488 ( $3 \mathrm{~K} 488$ : inside, launched at $33^{\circ} 24.500^{\prime} \mathrm{N} 139^{\circ} 40.500^{\prime} \mathrm{E}$ ) and 489 ( $3 \mathrm{~K}_{489}$ : outside, launched at $33^{\circ} 29.500^{\prime} \mathrm{N} 139^{\circ} 38.000^{\prime} \mathrm{E}$ ) were analysed in their entirety from the surface to the seafloor. There was too much ambient sunlight to reliably observe translucent animals using the ROV video footage in the shallow strata and the upper $100 \mathrm{~m}$ were therefore excluded from the analyses. In addition to the ROV dives, 'Shinkai 2000' Dive 1227 (2K1227: inside, launched at $33^{\circ} 24.500^{\prime} \mathrm{N}$ $139^{\circ} 41.000^{\prime} \mathrm{E}$ ) was reanalysed and species reidentified by the original observer (DJL in October 2016). Animals were identified to the lowest taxonomic level possible using the most recent taxonomic and field guides to each group (Bouillon et al., 2006; Kitamura, 2008; Kitamura et al., 2008a, b; Widmer et al., 2010; Lindsay et al., 2015; Minemizu et al., 2015). However, mesozooplankton such as copepods and larvaceans were unable to be analysed quantitatively. For the ROV dives, where descent speed was relatively constant, the amount of time spent observing in each $20 \mathrm{~m}$ depth strata was calculated and animal abundances normalized (Figure 2). The average observation time in each $20 \mathrm{~m}$ depth strata was $1 \mathrm{~min} 15 \mathrm{~s}$ during dive $3 \mathrm{~K}_{4} 88$ (range: $53-118 \mathrm{~s}$, total observing time $42.75 \mathrm{~min}$ ) and $1 \mathrm{~min} 13 \mathrm{~s}$ during dive ${ }_{3} \mathrm{~K} 489$ (range: $51-102 \mathrm{~s}$, total observing time $42.58 \mathrm{~min}$ ). Data were graphed using the software packages 'Aabel 3' (build 3.o.6, Gigawiz Ltd Co.) and 'ArcGIS' (Environmental Systems Research Institute, Inc.). Vertical profiles of environmental physicochemical parameters were made using the software package ' $R$ ' (build 3.3.2, R Development Core Team, 2008) (Figure 3).

\section{MORPHOLOGICAL OBSERVATIONS OF EARLERIA}

BRUUNI（NAVAS, 1969)

Two specimens of E. bruuni were collected during 'Shinkai 2000' Dive 1227 using the 6-canister suction sampler (samples $2 \mathrm{~K}_{122} \mathrm{SS}_{5}$ and $2 \mathrm{~K}_{1227} \mathrm{SS} 6$ ).

The specimens were transferred to a Petri dish for taxonomic observations under a shipboard dissecting microscope (Nikon SMZ-U, $0.75-7.5 \times$ ) outfitted with a video camera mounted on a C-0.45× Nikon TV lens and recorded in HDV format. Whenever magnification was changed, a ruler was placed beneath the Petri dish and recorded for information on scale. Still images of $720 \times 480$ pixels were captured in TIFF format (.tif). All images were processed in Adobe

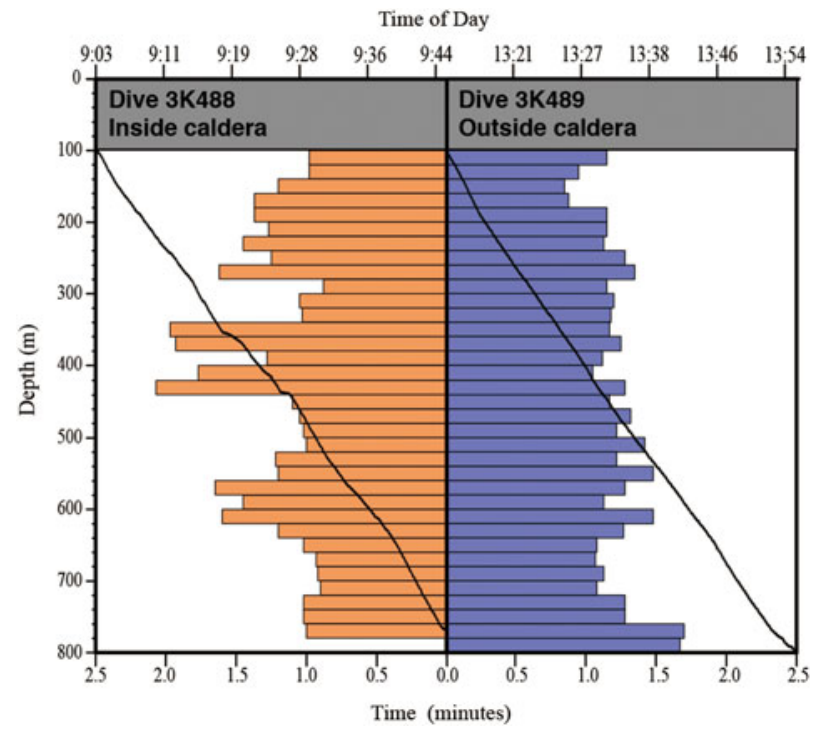

Fig. 2. Time spent observing inside and outside the Kurose Hole. Black lines show Dolphin- $3 \mathrm{~K}$ time vs depth dive profiles. Bar graphs show time spent observing for every $20 \mathrm{~m}$ depth stratum.

Photoshop CC (Ver. 2015) using the noise reduction filter, auto tone, auto contrast and auto colour on the default values. Size measurements in this study are based on the footage of living specimens. After observation, one specimen was preserved by freezing $\left(2 \mathrm{~K}_{122} \mathrm{SS}_{5} \mathrm{~b}\right)$ and the other one was preserved in $5 \%$ buffered formalin-seawater solution

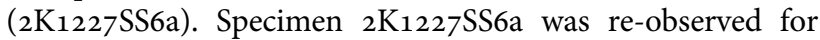
this study under two types of microscopes (Leica $\mathrm{MZ}_{1} 6 \mathrm{~F}$ with $2.0 \times$ lens, and OLYMPUS $\mathrm{IX}_{71}$ with $40.0 \times$ and $100.0 \times$ lens). The frozen sample was sequenced according to the method of Collins et al. (2008).

\section{RESULTS}

\section{Environmental profiles}

The caldera of the Kurose Hole was filled with warm water, with a minimum temperature of around $10^{\circ} \mathrm{C}$, during both the 'Dolphin-3K' and 'Shinkai 200o' dives. Higher water temperatures were observed in the surface layers during the 'Dolphin-3K' dives when the main axis of the Kuroshio Current lay above the dive sites (Figure 3). Extremely different vertical profiles of environmental parameters were apparent below $200 \mathrm{~m}$ depth between the inside $(3 \mathrm{~K} 488,2 \mathrm{~K} 1227)$ and outside $(3 \mathrm{~K} 489)$ of the Kurose Hole. Water density Sigma-T values were lower, while temperature, salinity and oxygen concentrations were higher below the edge of the rim inside the caldera. A strong signal (low salinity, high oxygen) indicating the presence of North Pacific Intermediate Water was observed in the 400-500 m depth strata outside the Kurose Hole.

\section{Comparison of macrozooplankton community inside and outside the Kurose Hole}

Comparative taxon richness and abundances of gelatinous macrozooplankton are shown in Figure 4, based on 

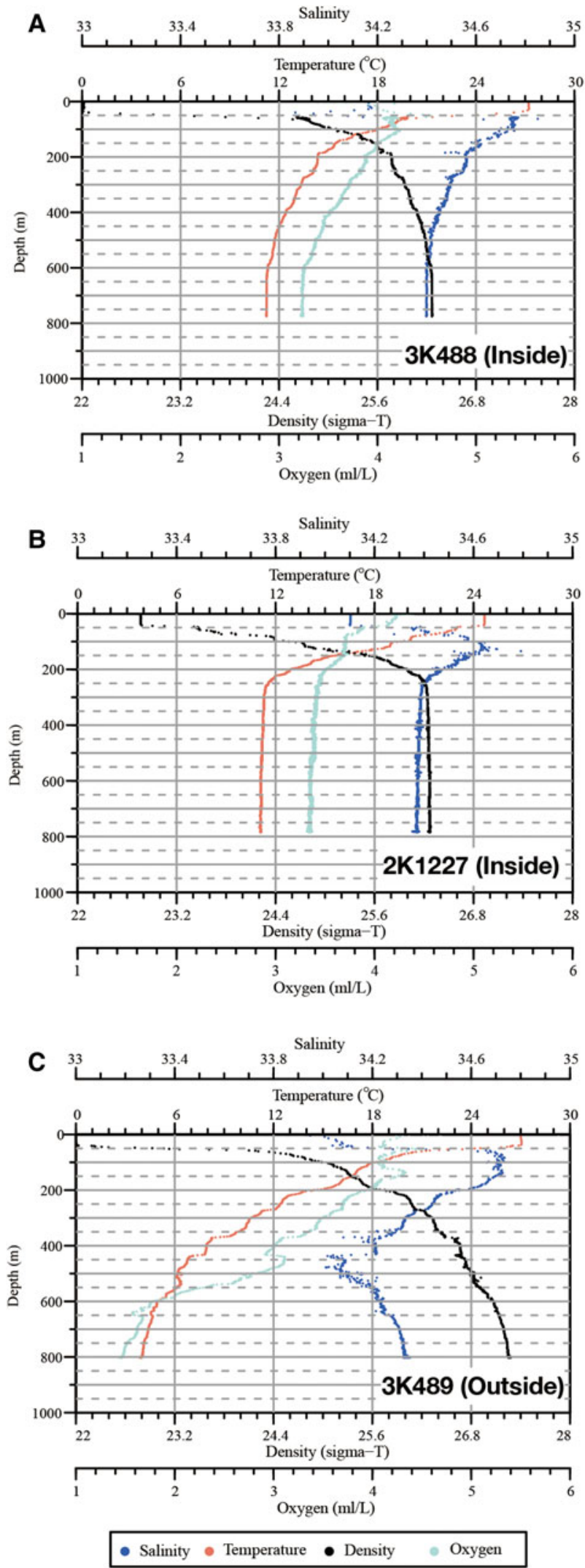

Fig. 3. Vertical profiles of temperature, salinity, oxygen and density vs depth. (A) $3 \mathrm{~K}_{4} 88$; (B) $2 \mathrm{~K}_{122}$; (C) $3 \mathrm{~K}_{4} 89$. observations made during descent for Dolphin-3K dives ${ }_{3} \mathrm{~K}_{4} 88$ and ${ }_{3} \mathrm{~K}_{4} 89$. Inside the Kurose Hole, the total number of individuals observed was about two times higher than outside, although taxon richness was much lower and scyphomedusae were not observed. Siphonophores and ctenophores were dominant taxa outside but not inside the Kurose Hole. Even though total observation times were the same during both dives (43 min total each), the number of taxa divided by the number of individuals observed inside and outside the Kurose Hole were 0.14 and 0.60 , respectively.

All gelatinous macrozooplankton occurrences are graphed in Figure 5, along with data from Dive $2 \mathrm{~K}_{1227}$ inside the caldera. A total of 38 taxa were identified in the three dives: 10 ctenophores, 12 siphonophores, 10 hydromeduse, two scyphomedusae, four others. Most individuals were distributed below $300 \mathrm{~m}$ depth. Some taxa seemed to be associated with warm waters, some with cold waters, and others were indeterminate. Hydromedusae were the most dominant 'warmtaxon', with abundances of a leptomedusa with four round gonads and a dark red manubrium being extremely high between 519-777 $\mathrm{m}$ depth. Two of the medusae were captured and identified under the microscope as Earleria bruuni (Navas, 1969), which has been redescribed below. These medusae were limited to the near-bottom layer, inside the isothermic water mass in the Kurose Hole (Figure 6). Nanomia bijuga (Delle Chiaje, 1844) was only observed inside the caldera (Figure 5). Colobonema sericeum Vanhöffen, 1902 occurred in every dive, always between 483 to $693 \mathrm{~m}$ depth. Solmissus incisa sensu lato and scyphomedusae species occurred only outside of the caldera. Bathocyroe spp. were only observed below $650 \mathrm{~m}$ depth outside the caldera. Two individuals of an undescribed Lobata taxon that lacks auricles were observed - one inside and the other outside the caldera, in different water masses. Salps were common in the warm water masses.

\section{SYSTEMATICS}

Order LEPTOTHECATA Cornelius, 1992

Family MITROCOMIDAE Haeckel, 1879 (part); Torrey, 1909 Leptomedusae with basis of manubrium attached to subumbrella along continuation of radial canals, four or more simple radial canals, marginal tentacles hollow, marginal cirri present in some genera, gonads oval or linear, only radial canals, open statocysts, no ocelli.

Genus Earleria Collins, Ross, Genzano \& Mianzan, 2006. Earleria Collins et al., 2006: 125. Type species: Earleria bruuni (Navas, 1969).

Mitrocomidae with four radial canals, with numerous open marginal statocysts, without ocelli and without marginal cirri.

Earleria bruuni (Navas, 1969)

(Figure 7)

\section{SYNONYMY}

Halistaura bruuni. Navas, 1969: 307-310.

Foersteria bruuni. Gili et al., 1998: 113-134.

Foersteria bruuni. Gili et al., 1999: 313-329.

Earleria bruuni. Collins et al., 2006: 125.

Foersteria bruuni. Lindsay \& Miyake, 2009: 424 [2 $\left.\mathrm{K}_{1227} \mathrm{SS}_{5} \mathrm{~b}\right]$.

Earleria bruuni. Widmer et al., 2010: 56. 


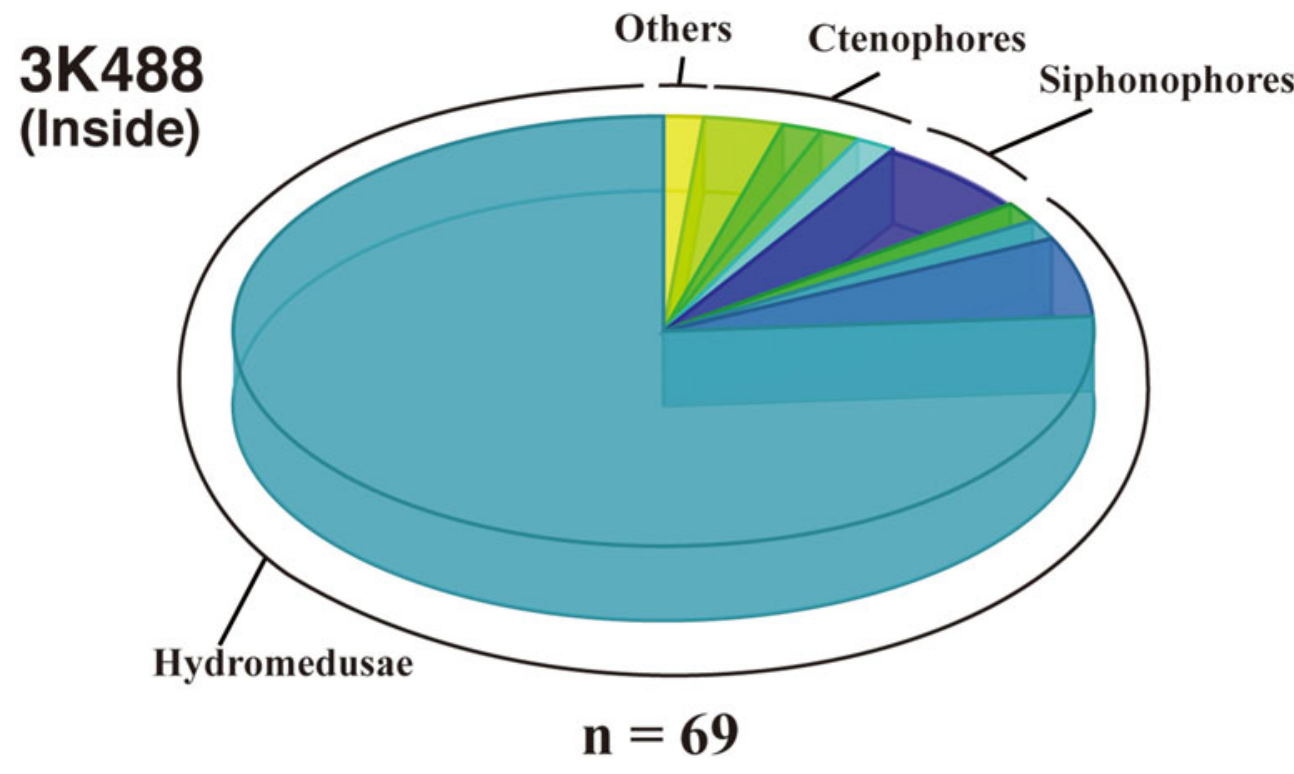

\section{Ctenophores}

$\square$ Lobata sp.

Undescribed Lobata sp.A

Bathocyroe spp.

Thalassocalyce spp.

Cydippida sp.

Euplokamissp.

Cydippid larvae

Beroe forskalii

Siphonophores

$\square$ Physonectae sp.

Apolemiidae sp.A

Apolemiidae sp.B

Calycophorae spp.

Forskalia asymmetrica

Bargmannia sp.

Prayidae spp.

Diphyomorph sp.

\section{Hydromedusae}

\section{K489}

\section{(Outside)}

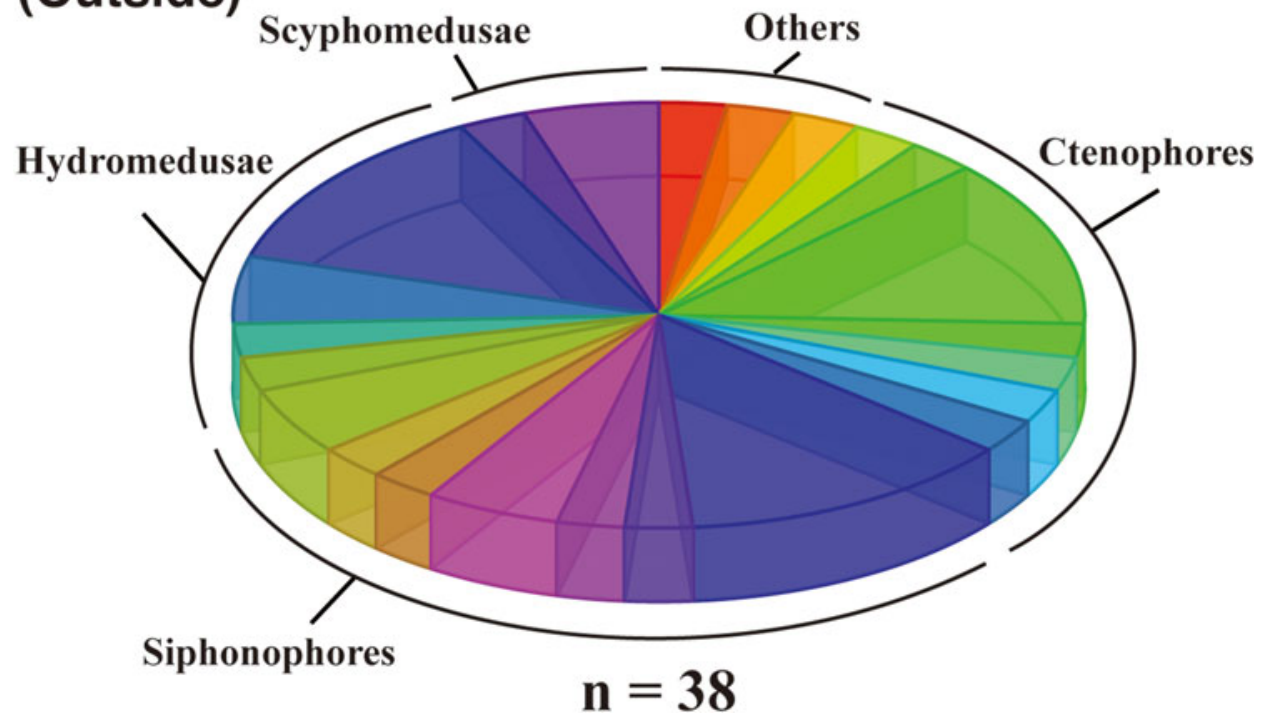

$\square$ Hydromedusae sp.

Rhopalonematidae sp.

Pandeidae sp.

Colobonema sericeum

Earleria bruuni

Solmissus incisa s.l.

Scyphomedusae

$\square$ Atolla sp.

Periphylla periphylla

Others

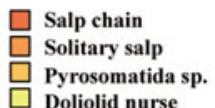

Fig. 4. Pie graphs comparing taxon richness and eveness of macrozooplankton between dives inside ( $\left.3 \mathrm{~K}_{4} 88\right)$ and outside ( $3 \mathrm{~K}_{4} 89$ ) the Kurose Hole.

\section{MATERIAL EXAMINED}

[2K1227SS5b: 032345] $2.5 \mathrm{~cm}$ diameter, mature female, inside Kurose Hole, Izu-Bonin Arc, North-western Pacific, $33^{\circ} 24.708^{\prime} \mathrm{N} 139^{\circ} 40.482^{\prime} \mathrm{E}, 615 \mathrm{~m}$ depth, $12: 27,11.11^{\circ} \mathrm{C}$, $33.41, \quad 7.67 \mathrm{ml} \mathrm{l}^{-1}, \quad 5 \%$ formalin. [2K1227SS6a: 032359] $2.4 \mathrm{~cm}$ diameter, mature male, inside Kurose Hole, IzuBonin Arc, North-western Pacific, $33^{\circ} 24.708^{\prime} \mathrm{N} 139^{\circ}$ $40.482^{\prime} \mathrm{E}, 532 \mathrm{~m}$ depth, $15: 45,11.16^{\circ} \mathrm{C}, 33.41,7.66 \mathrm{ml} \mathrm{l}^{-1}$, $-80^{\circ} \mathrm{C}$ frozen.

\section{DIAGNOSIS（EMENDED）}

No peduncle, number of tentacles $40-89$, with large cnidocysts in tentacle bulbs, gonads oval, laterally flattened, on distal half of radial canals, marginal statocysts open, one between each 2 successive tentacles.

\section{DESCRIPTION}

Umbrella flattened, mesoglea relatively thin, ex-umbrella transparent, sub-umbrella sub-hemispherical and relatively flat, transparent. No gastric peduncle. Base of manubrium quadratic. Short, small, quadratic manubrium dark red or brownish-coloured. Quadrangular mouth with four flared lips. 4 radial canals, whitish, translucent, straight, of uniform width. Four gonads on distal half of each radial canal, not extending onto upper half and cream-coloured, mature male

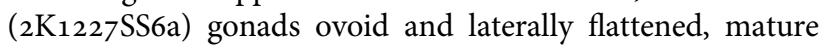
female $\left(2 \mathrm{~K}_{1227} \mathrm{SS}_{5} \mathrm{~b}\right)$ gonads sausage-shaped, longer than mature male gonads, split by a median groove. Number of tentacles were 85 and 89 , respectively. Nematocysts of two types - spherical nematocysts of mean diameter $2-3 \mu \mathrm{m}$ $(\mathrm{N}=10)$ and oblong nematocysts of approximate dimensions 


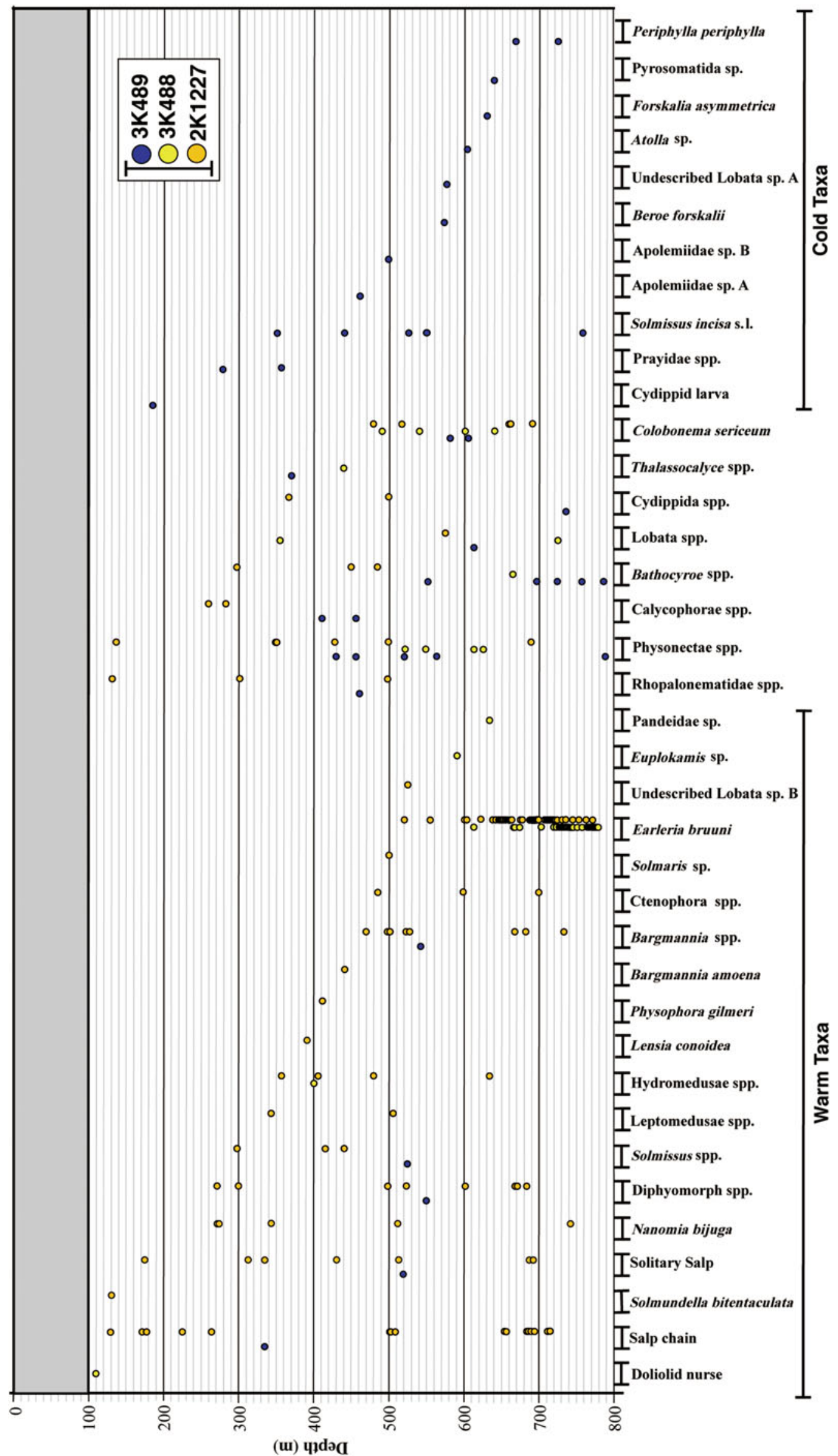

Fig. 5. Taxon occurrence records vs depth for the two 'Dolphin-3K' dives ( $3 \mathrm{~K}_{4} 88,{ }_{3} \mathrm{~K}_{4} 89$ ) and the 'Shinkai 20oo' dive (2K1227). 


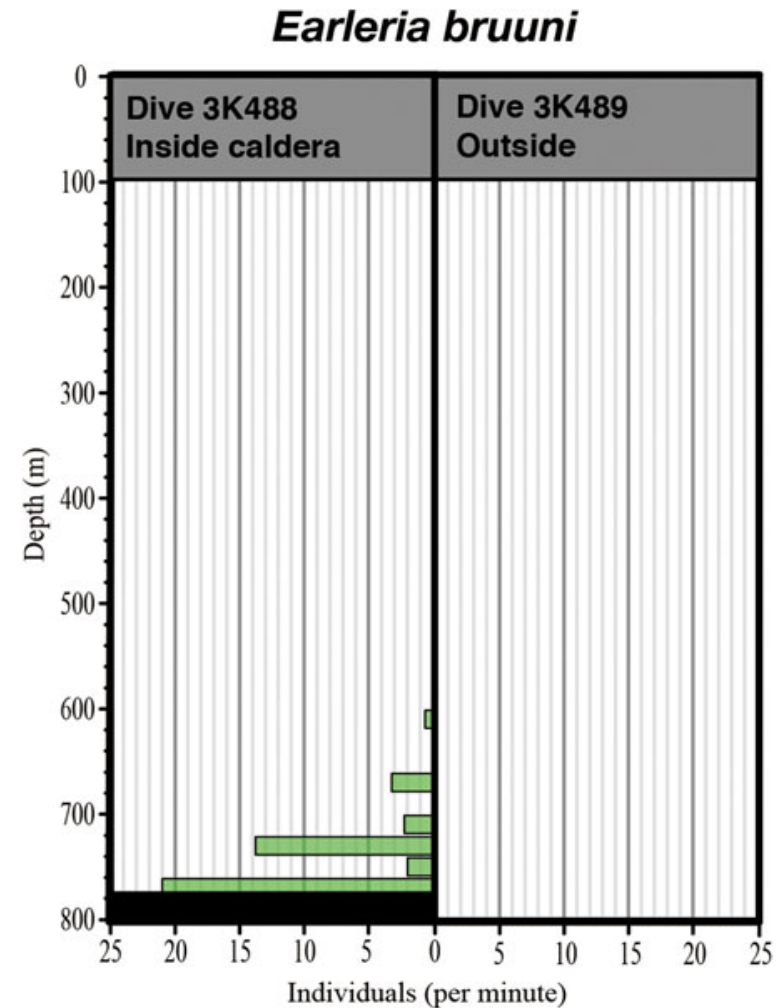

Fig. 6. Comparative vertical distribution of Earleria bruuni inside and outside the Kurose Hole.

$2 \times 4 \mu \mathrm{m}(\mathrm{N}=10)$. Without marginal cirri. Numerous open marginal statocysts, 1 between each 2 marginal tentacle bases.

\section{COLOUR}

Manubrium dark red, tentacle bulbs red pigmented and tentacles white.

\section{SIZE}

Maximum size to at least $2.5 \mathrm{~cm}$ diameter.

\section{COMPARISONS}

Earleria bruuni can be distinguished from other members of the genus by the combination of the following characters: flat umbrella, no peduncle, tentacle bulbs with cnidocysts and more than 40 tentacles.

\section{DISTRIBUTION}

Bay of Bengal (Navas, 1969), Kurose Hole (present material).

\section{REMARKS}

Earleria bruuni was described from the Bay of Bengal by Navas (1969) as Halistaura bruuni Navas, 1969. The only other record in the literature occurred some 50 years later off Japan as Foersteria bruuni (Navas, 1969), but was written in Japanese and gave no morphological description (Lindsay \& Miyake, 2009). The authors gave the species a Japanese name, 'Kurose kurage', meaning 'jellyfish from Kurose', based on one of the specimens from Shinkai 2000 dive 1227 in their checklist of mid-water jellyfishes from Japanese waters (Lindsay \& Miyake, 2009). Navas (1969) reported a total of 13 individuals (5.5-15.0 mm diameter), which included six mature males and four mature females.
Although only two specimens were captured in the present study, one was a mature male $(2.4 \mathrm{~cm}$ diameter $)$ and the other a mature female $(2.5 \mathrm{~cm}$ diameter $)$, both much larger than the specimens in the original description, and correspondingly having more tentacles. The number of tentacles in medusae of the genus Earleria are known to increase with growth (Widmer et al., 2010).

\section{DISCUSSIDN}

\section{Water mass and macro-zooplankton community}

Several different distributional patterns were observed Nanomia bijuga and salps were distributed over a wide depth range inside the caldera, Bargmannia spp. were similar but slightly deeper, while Earleria bruuni were patchy in their occurrence and were restricted to the nearbottom layer. On the other hand, Colobonema sericeum occurred both inside and outside the caldera but in higher numbers and over a wider depth range inside. The diel vertical migrator $N$. bijuga has been reported from the epipelagic and mesopelagic zones in many places in the Pacific Ocean (Hunt \& Lindsay, 1999; Minemizu et al., 2015), including down to $300 \mathrm{~m}\left(9^{\circ} \mathrm{C}\right)$ and $400 \mathrm{~m}\left(12^{\circ} \mathrm{C}\right)$ in the warm Celebes and Sulu Seas, respectively (Grossmann et al., 2015). In the present study, $N$. bijuga was observed only inside the caldera between $271 \mathrm{~m}\left(11.4^{\circ} \mathrm{C}\right)$ and $742 \mathrm{~m}\left(11.1^{\circ} \mathrm{C}\right)$ but it has also been reported from depths down to $800-900 \mathrm{~m}$ $\left(4.5^{\circ} \mathrm{C}\right)$ in Monterey Bay (Robison et al., 1998). The reason it was not observed outside the caldera may just be an artefact due to the high descent speed and low resolution of the ROV's camera compared with that of the human eye, since all occurrences during the present study were during the HOV survey. In contrast, the large, easily recognizable Colobonema sericeum was observed both inside $\left(483-693 \mathrm{~m}, 11.2-11.1^{\circ} \mathrm{C}\right)$ and outside $\left(584-606 \mathrm{~m}, 5.5-4.9^{\circ} \mathrm{C}\right)$ the caldera, with depth seemingly more important than temperature in determining its distribution and reinforcing its status as a cosmopolitan species, except in polar regions, the deep, warm Mediterranean (e.g. Larson et al., 1991; Minemizu et al., 2015) and possibly the Red Sea. It has been reported to occur between $500-600 \mathrm{~m}$ in the Celebes Sea at temperatures of $5.0-5.5^{\circ} \mathrm{C}$ and in the deep, warm Sulu Sea between $300-$ $400 \mathrm{~m}$ at temperatures of $12-13^{\circ} \mathrm{C}$ (Grossmann et al., 2015). Small rhopalonematid medusae that resembled C. sericeum were observed inside the Kurose Hole caldera at 133 and $302 \mathrm{~m}$ depth and although specimens were not captured to allow positive identification it may be that this species exhibits an ontogenetic migration to depth as it matures. Bathocyroe spp. were only observed below $550 \mathrm{~m}$ depth outside the caldera, even though the volume of water observed inside the caldera by the 'Shinkai 2000' was comparatively much greater than that observed by the ROV. Solmissus incisa sensu lato (including several different morphotypes of this species, see Lindsay et al., 2015) was similarly also only observed outside the caldera, even though it is easily recognizable to the naked eye even from a distance. The cold wateradapted deep-sea scyphomedusae Atolla spp. and Periphylla periphylla (Péron \& Lesueur, 1810) (Lindsay et al., 2004) were only observed in the deeper layers outside the caldera. 

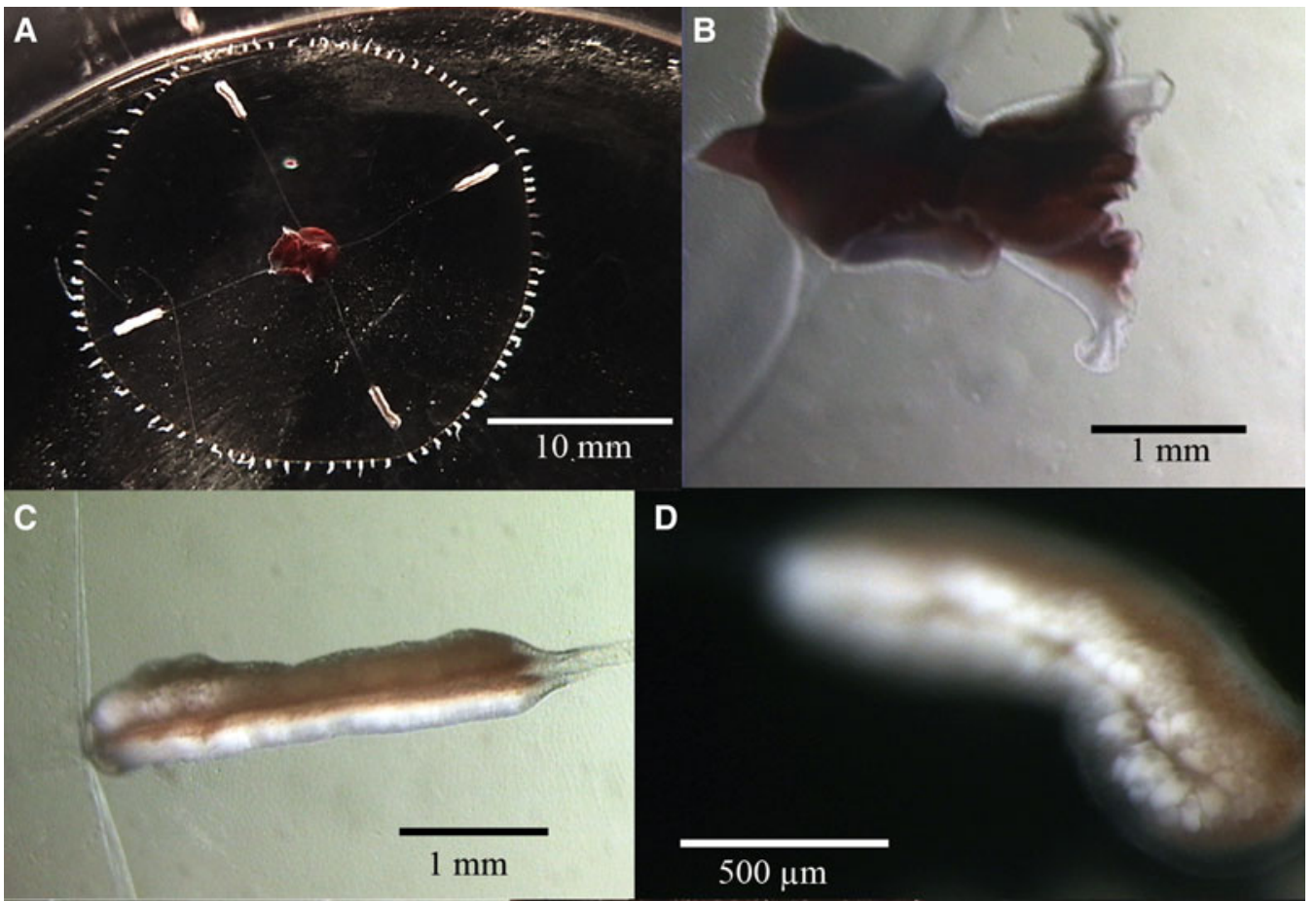

D

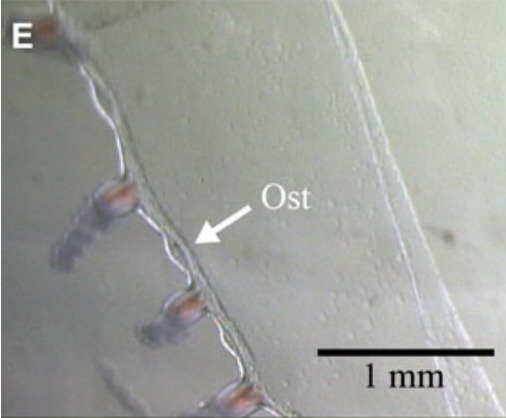

F

$500 \mu \mathrm{m}$

$1 \mathrm{~mm}$

H

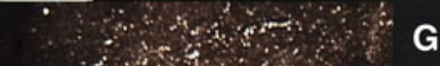

G

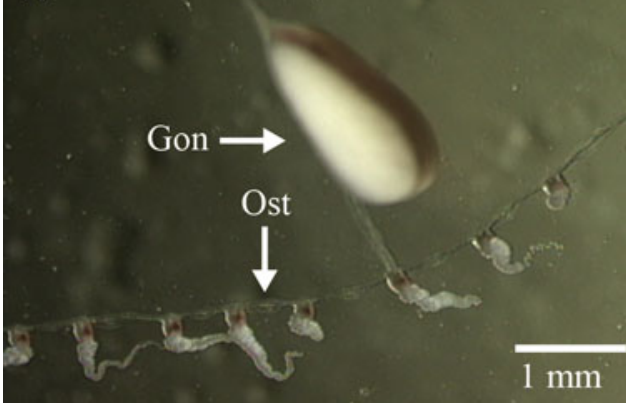

Fig. 7. Earleria bruuni (Navas, 1969). A-E: $2 \mathrm{~K}_{122}$ SS5 b. (A) aboral view of mature female; (B) close-up of manubrium; (C-D) close-up of gonads; (E) close-up of umbrella margin. F-I: $2 \mathrm{~K}_{1227}$ SS6a; (F) aboral view of mature male; (G) oral view of manubrium; (H) close-up of gonad and umbrella margin; (I) close-up of umbrella margin and tentacles. Ost, Open statocyst. Gon, Gonad.

Consequently, the present study revealed that the gelatinous macrozooplankton community inside the closed, warmer environment of the caldera was considerably different to that outside with regards to both the community composition and the vertical distributions of the fauna.

Iwabuchi et al. (1989) suggested that rather than the Kurose Hole being filled by a warm water mass derived from influx and vertical mixing of Kuroshio current waters into the caldera, it was more likely, based on the salinity values inside the caldera being lower than the values of Kuroshio Water, that the internal water mass was formed through geothermal heating and subsequent vertical mixing. The low salinity values presumably derive from the pore waters of the subducted sediments from which the geothermally heated waters originate. The occurrence of macrozooplanktonic taxa in the deeper waters of the caldera is therefore considered not to be due to active transport to deeper depths within a surface- or subsurface-derived current of Kuroshio origin but rather due to movements by the animals themselves. This warm, lower salinity water mass seems to provide an 'oasis' for the gelatinous macrozooplankton living inside. 


\section{Earleria bruuni}

Earleria bruuni occurred at a high population density, being observed between 519 and $777 \mathrm{~m}$ depth, where salinity ranged from 34.38 to 34.40 and temperature was stable at $11.1^{\circ} \mathrm{C}$. They were limited to the near bottom layer, where isothermic water occurred inside the Kurose Hole caldera. Minimum depth distribution revealed by the 'Shinkai 2000' dive was slightly shallower $(519 \mathrm{~m})$ than by the ROV 'Dolphin-3K' $(612 \mathrm{~m})$ but as only one dive was carried out by each platform the difference in observed distributions could just as easily have been due to inherent patchiness as to the greater ease of detecting rare (low density) individuals through the greater volume scanned by the human eye. According to Navas (1969) and Navas \& Vannucci (1991), E. bruuni were collected in the 125-1000 m depth strata with the most accurate depth record being for $125-250 \mathrm{~m}$ depth. In that strata salinity ranged from 34.7 to 35.0 and temperature from 12.2 to $17.35^{\circ} \mathrm{C}$ (Navas, 1969), being sandwiched between Bay of Bengal Surface Water (BBSW) and Bay of Bengal Sub Surface Water (BBSSW) in the maximum salinity layer and E. bruuni were never caught in the surface layer (Navas \& Vannucci, 1991). Earleria bruuni from the Kurose Hole and the Bay of Bengal were observed under similar water temperatures but different salinities and it can therefore be characterized as a warm water mass species. Although E. bruuni was not observed outside the caldera, based on the similar environmental factors to those associated with its occurrence in the Bay of Bengal, it should be able to occur. Their dark pigmented gut suggests that they are adapted to catch deep-living bioluminescent prey and we speculate that the E. bruuni report from the Bay of Bengal was due to them being upwelled from the near-bottom layer to near the surface.

Most of the reports on the occurrence of congeners are from semi-closed environments such as canyons or fjords. Earleria antoniae (Foersteria antoniae: Gili et al., 1998; Bouillon et al., 2000) and Earleria araiae (Foersteria araiae: Gili et al., 1999; Bouillon et al., 2000) were reported from canyons in the Mediterranean sea. Earleria purpurea (Foersteria purpurea: Mackie, 1985; Larson et al., 1992) were reported as one of the benthopelagic species present in fjords of British Columbia in the 50-450 m depth strata, and deeper than $200 \mathrm{~m}$ depth in Monterey Bay. Earleria quadrata (Foersteria quadrata, Hosia \& Pagès, 2007) were reported from a fjord in Norway deeper than $500 \mathrm{~m}$. In this respect, it can be hypothesized that the genus Earleria favours deep, isolated water masses. An advantage of the steep-walled concave geography of the fjords and canyons they inhabit is that the particle concentration should increase with depth. Indeed, the cross-sectional area at the $700 \mathrm{~m}$ isobath in the Kurose Hole is 30 times smaller than at the caldera rim, and this would act to concentrate sinking particles and vertically migrating plankton, increasing ambient food concentrations.

In addition, the detailed life cycle of the congeneric species Earleria corachloeae has been revealed and their polyps were found on the head of the midwater shrimp Pasiphaea pacifica Rathbun, 1902 (Widmer et al., 2010). Correspondingly, Pasiphaea spp. were observed during all dives in the present study, some individuals were passing through the patch of E. bruuni inside the Kurose Hole between 730 and $777 \mathrm{~m}$ depth. In terms of reproduction, the topography of the Kurose Hole retains the water it contains and the organisms within it, presumably enhancing blooming of E. bruuni and providing favourable substrates for the polyps.

\section{Differences between ROV vs HOV observations}

In order to clarify the distribution of gelatinous macrozooplankton, which are transparent and fragile animals, the advantages and disadvantages of various survey methods must be assessed. Direct observations, such as are possible with ROV or HOV dives, can provide accurate information on the distribution of gelatinous macrozooplankton and associations with other organisms, but the amount of data/volume of water sampled is not as high as with net sampling and not all specimens can be identified to species level. Furthermore, when community structure is surveyed through net sampling $v s$ ROV observation, the sampled or observed species composition is different (Raskoff et al., 2010), because of individual sizes, fragility and/or transparency. Likewise, differences between ROV observations and HOV observations were found in the present study because a human's eyes have better resolution than that of a video camera. During 'Shinkai 2000' dive 1227, more individuals were observed and more species-level identifications were possible than with the 'Dolphin-3K' dives. However, the technical restrictions imposed by the ROV actually lead to a more quantitative evaluation, since camera angle, imaged volume, etc. are restrained and recorded, unlike with the human eye. Consequently, it seems that HOV investigations by an experienced researcher are effective for biodiversity surveys, while ROV investigations may be more efficient for an environmental impact assessment (EIA), which requires a repeatable, uniform method. With the development of high resolution imaging technology such as 4 and $8 \mathrm{~K}$ video camera systems, we can expect more detailed and quantitative investigation methods to be developed for gelatinous macrozooplankton surveys, finally bridging the gap between naked-eye and camera-based investigations.

\section{CONCLUSIONS}

Comparative ROV dives revealed that semi-closed systems such as deep-sea calderas can have unique environmental factors and gelatinous macrozooplankton communities. In the Kurose Hole, Izu-Ogasawara Islands, extremely low taxon diversity was found inside the caldera, and large numbers of the leptomedusa Earleria bruuni were observed inside the caldera, being the predominant species. Blooming of Earleria bruuni was also observed during the additional HOV dive, which was performed 3 weeks later. Surprisingly, the current report of E. bruuni is the first in 50 years, even though the medusa was extremely abundant in the Kurose Hole. Two major causes for this phenomenon may be, firstly, the isolated habitat formed inside the caldera with an isothermic warm water mass when compared with outside the caldera may be a highly suitable habitat for the medusa, and, secondly, the steep, concave topography could concentrate sinking particles and vertically migrating plankton, thereby increasing ambient food concentrations and leading to the observed blooming of E. bruuni. 


\section{ACKNOWLEDGEMENTS}

We are grateful to the reviewers for critical and constructive comments on the manuscript. Thanks are due to the captain, crew and scientific parties of RV 'Natsushima' cruises NToo-10 and NToo-11. We also thank Dr Hiroyuki Yamamoto of the Environmental Impact Assessment Research Group, within the Research and Development Center for Submarine Resources, JAMSTEC, for his support. This study is a contribution to the International Network for Scientific Investigations of Deep-Sea Ecosystems (INDEEP), and the Deep Ocean Stewardship Initiative (DOSI). Contributors: Maps of the research areas used to assemble Figure 1 were plotted by Kazuya Kitada using the software package GMT: The Generic Mapping Tools (Wessel \& Smith, 2013). Vertical profiles of environmental physicochemical parameters (Figure 3) were plotted by Kei Sunahara using the software package R. A draft of Figure 5 was prepared by Ryota Nakajima using the software package ArcGIS.

\section{FINANCIAL SUPPDRT}

This work was partially funded by the Japan Society for the Promotion of Science (JSPS) KAKENHI: (grant numbers 24248032, 26304030 and 23405031) and JST grant CREST, the fund for Interdisciplinary Collaborative Research by the Atmosphere and Ocean Research Institute, University of Tokyo, and the Cross-ministerial Strategic Innovation Promotion Program (SIP) for the Development of Newgeneration Research Protocols for Submarine Resources; Core Research for Evolutionary Science and Technology.

\section{REFERENCES}

Abe Y., Yamaguchi A., Matsuno K., Kono T. and Imai I. (2014) Short-term changes in the population structure of hydromedusa Aglantha digitale during the spring phytoplankton bloom in the Oyashio region. Bulletin of Fisheries Sciences, Hokkaido University $64,71-81$.

Arkhipchuk V.V., Blaise C. and Malinovskaya M.V. (2006) Use of hydra for chronic toxicity assessment of waters intended for human consumption. Environmental Pollution 142, 200-211.

Boschen R.E., Rowden A.A., Clark M.R., Barton S.J., Pallentin A. and Gardner J.P.A. (2015) Megabenthic assemblage structure on three New Zealand seamounts: implications for seafloor massive sulfide mining. Marine Ecology Progress Series 523, 1-14

Boschen R.E., Rowden A.A., Clark M.R. and Gardner J.P.A. (2013) Mining of deep-sea seafloor massive sulfides: a review of the deposits, their benthic communities, impacts from mining, regulatory frameworks and management strategies. Ocean and Coastal Management $84,54-67$.

Bouillon J., Gravili C., Pagès F., Gili J.-M. and Boero F. (2006) An introduction to Hydrozoa. Paris: Muséum National d'Histoire Naturelle.

Bouillon J., Pagès F., Gili J.-M., Palanques A., Puig P. and Heussner S. (2000) Deep-water Hydromedusae from the Lacaze-Duthiers submarine canyon (Banyuls, northwestern Mediterranean) and description of two new genera, Guillea and Parateclaia. Scientia Marina $64\left(\mathrm{~S}_{1}\right), 87-95$.
Collins A.G., Bentlage B., Lindner A., Lindsay D., Haddock S.H.D., Jarms G., Norenburg J.L., Jankowski T. and Cartwright P. (2008) Phylogenetics of Trachylina (Cnidaria: Hydrozoa) with new insights on the evolution of some problematical taxa. Journal of the Marine Biological Association of the United Kingdom 88, 1673-1685.

Collins J.S.H., Ross A.J., Genzano G. and Mianzan H. (2006) Earleria gen. nov. \& Gabriella gen. nov., replacement names for Foersteria Arai \& Brinckmann-Voss, 1980 (Cnidaria, Hydrozoa, Mitrocomidae) and Foersteria Wehner, 1988 (Crustacea, Decapoda, Prosopidae), junior homonyms of Foersteria Szépligeti, 1896 (Insecta Hymenoptera, Braconidae). Bulletin of the Mizunami Fossil Museum $33,125-126$.

Gili J.-M., Bouillon J., Pagès F., Palanques A. and Puig P. (1999) Submarine canyons as habitats of prolific plankton populations: three new deep-sea Hydroidomedusae in the western Mediterranean. Zoological Journal of the Linnean Society 125, 313-329.

Gili J.-M., Bouillon J., Pagès F., Palanques A., Puig P. and Heussner S. (1998) Origin and biogeography of the deep-water Mediterranean Hydromedusae including the description of two new species collected in submarine canyons of Northwestern Mediterranean. Scientia Marina 62, 113-134.

Grossmann M.M., Nishikawa J. and Lindsay D.J. (2015) Diversity and community structure of pelagic cnidarians in the Celebes and Sulu Seas, southeast Asian tropical marginal seas. Deep Sea Research I 100, 54-63. doi: 10.1016/j.dsr.2015.02.005

Hosia A. and Pagès F. (2007) Unexpected new species of deep-water Hydroidomedusae from Korsfjorden, Norway. Marine Biology 151, $177-184$.

Hunt J.C., Hashimoto J., Fujiwara Y., Lindsay D.J., Fujikura K., Tsuchida S. and Yamamoto T. (1997) The development, implementation, and establishment of a meso-pelagic and bentho-pelagic biological survey program using submersibles in the seas around Japan. JAMSTEC Journal of Deep Sea Research 13, 675-685.

Hunt J.C. and Lindsay D.J. (1999) Methodology for creating an observational database of midwater fauna using submersibles: results from Sagami Bay, Japan. Plankton Biology and Ecology 46, 75-87.

Iwabuchi Y., Ashi J. and Fujioka K. (1989) Geological and geomorphological survey of the Kurose Hole, north of the Hachijo Island. JAMSTEC Journal of Deep Sea Research 5, 37-45. [In Japanese]

Kitamura M. (2008) Urochordata. In Fujikura K., Okutani T. and Maruyama T. (eds) Deep-sea life - biological observations using research submersibles. Kanagawa: Tokai University Press, pp. 351355. [In Japanese]

Kitamura M., Miyake H. and Lindsay D.J. (2008a) Cnidaria. In Fujikura K., Okutani T. and Maruyama T. (eds) Deep-sea life - biological observations using research submersibles. Kanagawa: Tokai University Press, pp. 295-320. [In Japanese]

Kitamura M., Miyake H., Lindsay D.J. and Horita T. (2008b) Ctenophora. In Fujikura K., Okutani T. and Maruyama T. (eds) Deep-sea life - biological observations using research submersibles. Kanagawa: Tokai University Press, pp. 321-328. [In Japanese]

Larson R.J., Matsumoto G.I., Madin L.P. and Lewis L.M. (1992) Deepsea benthic and benthopelagic medusae: recent observations from submersibles and a remotely operated vehicle. Bulletin of Marine Science 51, 277-286.

Larson R.J., Mills C.E. and Harbison G.R. (1991) Western Atlantic midwater hydrozoan and scyphozoan medusae: in situ studies using manned submersibles. Hydrobiologia 216/217, 311-317.

Lindsay D.J., Furushima Y., Miyake H., Kitamura M. and Hunt J.C. (2004) The scyphomedusan fauna of the Japan Trench: preliminary results from a remotely-operated vehicle. Hydrobiologia 530/531, $537-547$. 
Lindsay D.J. and Hunt J.C. (2005) Biodiversity in midwater cnidarians and ctenophores: submersible-based results from deep-water bays in the Japan Sea and north-western Pacific. Journal of the Marine Biological Association of the United Kingdom 85, 503-517.

Lindsay D.J. and Miyake H. (2009) A checklist of midwater cnidarian and ctenophores from Japanese waters: species sampled during submersible surveys from 1993-2008 with notes on their taxonomy. Kaiyo Monthly 41, 417-438. [In Japanese]

Lindsay D.J., Umetsu M., Grossmann M., Miyake H. and Yamamoto H. (2015) The gelatinous macroplankton community at the Hatoma Knoll hydrothermal vent. In Ishibashi J., Okino K. and Sunamura M. (eds) Subseafloor biosphere linked to global hydrothermal systems; TAIGA Concept. Tokyo: Springer, pp. 639-666, doi 10.1007/978-4431-54865-2_51.

Mackie G.O. (1985) Midwater plankton of British Columbia studied by submersible PISCES IV. Journal of Plankton Research 7, 753-777.

Minemizu R., Kubota S., Hirano Y. and Lindsay D. (2015) A photographic guide to the jellyfishes of Japan. Tokyo: Heibonsha. [In Japanese]

Nakajima R., Yamamoto H., Kawagucci S., Takaya Y., Nozaki T., Chen C., Fujikura K., Miwa T. and Takai K. (2015) Post-drilling changes in seabed landscape and megabenthos in a deep-sea hydrothermal system, the Iheya North field, Okinawa Trough. PLoS ONE 10 e0123095, 22. doi: 10.1371/journal.pone.0123095.

Navas D. (1969) Halistaura bruuni sp. nov. (Leptomedusae, Mitrocomidae) with notes on its distribution and ecology. Marine Biology 2, 307-310.

Navas D. and Vannucci M. (1991) The hydromedusae and water masses of the Indian Ocean. Boletim do Instituto Oceanográfico 39, 25-60.

Phillips B.T. (2017) Beyond the vent: new perspectives on hydrotherma plumes and pelagic biology. Deep Sea Research II 137, 480-485. doi: 10.1016/j.dsr2.2016.10.005.

Purcell J.E. (2005) Climate effects on formation of jellyfish and ctenophore blooms: a review. Journal of the Marine Biological Association of the United Kingdom 85, 461-476.

Purcell J.E. (2012) Jellyfish and ctenophore blooms coincide with human proliferations and environmental perturbations. Annual Review of Marine Science 4, 209-235.

Quinn B., Gagné F. and Blaise C. (2012) Hydra, a model system for environmental studies. International Journal of Developmental Biology 56, 613-625.
Raskoff K.A., Hopcroft R.R., Kosobokova K.N., Purcell J. and Youngbluth M. (2010) Jellies under ice: ROV observations from the Arctic 2005 hidden ocean expedition. Deep Sea Research II 57, $111-126$.

R Development Core Team (2008) $R$ : a language and environment for statistical computing. Vienna: $\mathrm{R}$ Foundation for Statistical Computing. http://www.R-project.org.

Robison B.H., Reisenbichler K.R., Sherlock R.E., Silguero J.M.B. and Chavez F.P. (1998) Seasonal abundance of the siphonophore, Nanomia bijuga, in Monterey Bay. Deep Sea Research II 45, $1741-$ 1751.

Robison B.H., Sherlock R.E. and Reisenbichler K.R. (2010) The bathypelagic community of Monterey Canyon. Deep Sea Research II 57, $1551-1556$

Uye S-I. (2008) Blooms of the giant jellyfish Nemopilema nomurai: a threat to the fisheries sustainability of the East Asian Marginal Seas. Plankton and Benthos Research 3, 125-131.

Van Dover C.L. (2014) Impacts of anthropogenic disturbances at deepsea hydrothermal vent ecosystems: a review. Marine Environmental Research 102, 59-72.

Wessel P., Smith W.H.F., Scharroo R., Luis J. and Wobbe F. (2013) Generic mapping tools: improved version released. Eos 94, 409-410.

Widmer C.L., Cailliet G. and Geller J. (2010) The life cycle of Earleria corachloeae n. sp. (Cnidaria: Hydrozoa) with epibiotic hydroids on mid-water shrimp. Marine Biology 157, 49-58.

and

Yuasa M., Murakami F., Saito E. and Watanabe K. (1991) Submarine topography of seamounts on the volcanic front of the IzuOgasawara (Bonin) Arc. Bulletin of the Geological Survey of Japan $42,703-743$.

\section{Correspondence should be addressed to:}

M. Hidaka-Umetsu

Environmental Impact Assessment Research Group, Research and Development Center for Submarine Resources, Japan Agency for Marine-Earth Science and Technology (JAMSTEC),

2-15 Natsushima-cho, Yokosuka City, Kanagawa Prefecture 237-0061, Japan

email: mitsukou@jamstec.go.jp 